\title{
Intelligent HEV Fuzzy Logic Control Strategy Based on Identification and Prediction of Drive Cycle and Driving Trend
}

\author{
Limin Niu, Hongyuan Yang, Yuhua Zhang \\ School of Mechanical Engineering, Anhui University of Technology, Maanshan, China \\ Email: niulmdd@163.com, dl33566410@163.com, yhzhang@ahut.edu.cn
}

Received 5 September 2015; accepted 16 October 2015; published 23 October 2015

\begin{abstract}
Real-time drive cycles and driving trends have a vital impact on fuel consumption and emissions in a vehicle. To address this issue, an original and alternative approach which incorporates the knowledge about real-time drive cycles and driving trends into fuzzy logic control strategy was proposed. A machine learning framework called MC_FRAME was established, which includes two neural networks for self-learning and making predictions. An intelligent fuzzy logic control strategy based on the MC_FRAME was then developed in a hybrid electric vehicle system, which is called FLCS_MODEL. Simulations were conducted to evaluate the FLCS_MODEL using ADVISOR. The simulation results indicated that comparing with the default controller on the drive cycle NEDC, the FLCS_MODEL saves $12.25 \%$ fuel per hundred kilometers, with the HC emissions increasing by $22.7 \%$, the $\mathrm{CO}$ emissions reducing by $16.5 \%$, the $\mathrm{NO}_{\mathrm{x}}$ emissions reducing by $37.5 \%$ and with the PM emissions reducing by $12.9 \%$. A conclusion can be drawn that the proposed approach realizes fewer fuel consumption and less emissions.
\end{abstract}

\section{Keywords}

HEV, Neural Network, Drive Cycle Prediction, Driving Trend Prediction

\section{Introduction}

Speaking globally, emission regulations and fuel consumption limits are becoming stricter, thus energy saving and environment protecting are the common direction for the whole wide world industry. It's one of the biggest issues for automobile enterprises to raise fuel economy and reduce emissions. It is the best or the only solution for us to deal with energy consumption and emissions by developing hybrid electrical technologies. As for new energy vehicles, there are no problems in these two aspects. But the popularity of the infrastructure construction for new energy vehicles will need such a long time [1]. As for hybrid electrical vehicle technologies, the evolution may be realized in the following several directions: 1) Optimize the structure of the vehicle power train system; 2) Improve the performance of electrical/electronic components; 3) Optimize control strategy of a vehicle. In this paper, we tried to do research on optimizing control strategy. Studies show that real-time drive cycles and driving trends has a vital impact on fuel consumption and exhaust emissions of a vehicle [2] [3]. The 
HEV control strategies can be divided into two categories; one is based on mathematical rules, the other on the optimal principles. Most of these control strategies are established according to the mathematical models and driving experiences, without combining with real-time drive cycles and driving trends, which makes those strategies lack adaptability, robustness and intelligence with respect to real-time driving conditions. So control strategies with the real-time predicted drive cycles and driving trends have a great potential for further energy conservation and emissions reduction.

The research on the combination of HEV control strategies and drive cycle forecast has achieved some progresses in recent years, but it's still in the basic stage. In foreign countries, Lee J, et al. proposed a multi-mode driving controller of a parallel hybrid electric vehicle using driving pattern recognition [4]. Langari, et al. proposed an intelligent energy management agent called IEMA for parallel hybrid vehicles which incorporates a driving situation component. This identical driving information is subsequently used to determine the power split strategy, which is shown to lead to enhanced fuel economy and reduced emissions [5] [6]. In China, Wang Qingnian, et al. trained a neural network to generate the inference rules of the driving intention. And a new hybrid vehicle control strategy was then proposed based on the driving intention [7]. Lv Zhiren classified the urban driving conditions in Dalian city and used a fuzzy logic recognition method to identify Dalian driving conditions. The driving intention of the driver was predicted by another fuzzy component. All this information was used by the proposed control strategy to determine the power split [8]. The paper [9] took advantage of the extreme learning machine to identify the working condition and fuzzy logic control algorithm to identify the driving intention. An energy management strategy for the plug-in hybrid electric vehicles based on the recognition of driving intention and working condition was then proposed. Jinyan, et al. used Markov model to predict the driving patterns (parking, charging the battery, engine working only, motor working only, both engine and motor working and vehicle braking energy recovery), and then improved the fuzzy logic control strategy with the predicted information [10]. At present, most of the researches only focus on the fuzzy logic algorithm to predict the driving cycle, the driving intention or the driving patterns. And most of the energy management control strategies are optimized by using the forecast data. This paper focuses on the use of neural networks to deal with the problems of driving cycle identification and driving trend identification. A new fuzzy logic control strategy is optimized by using the identical information.

We built a machine learning framework MC_FRAME as a prediction module, which contains two neural networks, NNET_SDC and NNET_DT. NNET_SDC is used to predict the drive cycles in a few seconds, and NNET_DT is used to predict the driving trends. In addition, an intelligent fuzzy logic control strategy was developed. We used the predicted data as inputs of the intelligent controller, and made optimal power matched control rules to maintain the battery SOC values in an appropriate range, make sure the output torque almost equal to optimal torque of engine and to ensure that motor works in an ideal area. We focus on implementing an intelligent fuzzy logic control strategy that incorporates the knowledge about real-time drive cycles and driving trends to improve the intelligent level of the control strategy and to get lower fuel consumption and fewer emissions.

This paper is written as follows. Section 2 introduces the machine learning framework MC_FRAME as a prediction module. Section 3 presents the intelligent fuzzy logic control strategy we built and the online implementation of intelligent controller FLCS_MODEL in a parallel hybrid electrical vehicle. Section 4 performs simulations in ADVISOR to evaluate the intelligent controller FLCS_MODEL. Section 5 is the conclusion.

\section{Machine Learning Framework MC_FRAME}

\subsection{A Neural Network for the Prediction of Drive Cycles}

In this paper, we use the set of eleven standard drive cycles developed by the Sierra Research Inc. to represent all kinds of driving conditions in urban areas for passenger vehicles [11]. The set of eleven standard drive cycles are divided into four categories depending on the road types and traffic congestion levels: 1) freeway; 2) freeway ramp; 3) arterial; 4) local roadway. According the level of service (LOC), i.e., driving speed, various facilities and congestion levels, freeway and arterial are further divided. Six types of LOS are labeled from A through F with A representing the best level of service, i.e., the best operating conditions, and $\mathrm{F}$ the worst. The set of 11 standard drive cycles are labeled as SDC[i], (i = 1, 2...11), for the convenience to describe, as shown in Table $\mathbf{1}$.

The Operating Principles of the Neural Learning for Drive Cycles: Supposed that DC $(t)$ is a real-time drive cycle of a certain trip that a driver is going to go through, $\left(t \in\left[0, t_{e}\right]\right.$, where $t_{e}$ is the ending moment of the drive 
Table 1. The set of eleven standard drive cycles.

\begin{tabular}{|c|c|c|c|c|}
\hline Standard Drive Cycles & $\begin{array}{l}\text { Average speed, } \\
\mathrm{V}_{\text {ave }}(\mathrm{km} / \mathrm{h})\end{array}$ & $\begin{array}{l}\text { Maximum speed, } \\
\mathrm{V}_{\max }(\mathrm{km} / \mathrm{h})\end{array}$ & $\begin{array}{c}\text { Average acceleration, } \\
A_{\text {ave }}\left(\mathrm{m} / \mathrm{s}^{2}\right)\end{array}$ & $\begin{array}{l}\text { Length, } \\
\text { (s) }\end{array}$ \\
\hline Freeway A: SDC [1] & 109.10 & 127.98 & 1.02 & 399.00 \\
\hline Freeway B: SDC [2] & 107.68 & 126.08 & 1.30 & 366.00 \\
\hline Freeway C: SDC [3] & 107.09 & 126.72 & 1.52 & 448.00 \\
\hline Freeway D: SDC [4] & 105.00 & 124.82 & 1.30 & 433.00 \\
\hline Freeway E: SDC [5] & 92.05 & 119.78 & 1.79 & 471.00 \\
\hline Freeway F: SDC [6] & 52.51 & 102.76 & 1.79 & 536.00 \\
\hline Freeway Ramp: SDC [7] & 55.68 & 101.95 & 2.55 & 266.00 \\
\hline Arterial A-B: SDC [8] & 39.91 & 94.78 & 2.23 & 737.00 \\
\hline Arterial C-D: SDC [9] & 30.90 & 79.66 & 2.55 & 629.00 \\
\hline Arterial E-F: SDC [10] & 18.67 & 64.21 & 2.59 & 504.00 \\
\hline Local roadway: SDC [11] & 20.76 & 61.64 & 1.65 & 525.0 \\
\hline
\end{tabular}

cycle). At any time $t$, the current drive cycle DC ( $t$ ) belongs to one of eleven standard drive cycles SDC[i] which represent all kinds of driving conditions in urban areas for passenger vehicles. That is to say, DC $(t) \in\{$ SDC (i) $\mid i=1 \ldots 11\}$. A neural network for the prediction of drive cycles named NNET_SDC was developed to firstly identify to which the eleven standard drive cycles SDC[i] the real-time drive cycle DC $(t)$ belongs in the time segment $\left[t_{C}-\Delta t_{D C}, t_{C}\right]$, where $t_{C}$ is the current time instance, $\Delta t_{D C}$ is the window size of the time segment used for the prediction of drive cycles. Then assume that the drive cycle which a vehicle will be in over the time period $\left[t_{C}, t_{C}+\Delta t_{P}\right]$ is the same as the drive cycle which the vehicle was in over the time period $\left[t_{C}-\Delta t_{D C}, t_{C}\right]$ in the past. That is to say, we identify to which the eleven standard drive cycles SDC[i] the drive cycle over the time period $\left[t_{C}-\Delta t_{D C}, t_{C}\right]$ in the past belongs, and use the identical SDC[i] to represent the drive cycle which a vehicle will be in over the time period $\left[t_{C}, t_{C}+\Delta t_{P}\right]$ as the prediction of drive cycle, where $\Delta t_{p}$ is the time interval over which the prediction is made. We took $\Delta t_{D C}=50 \mathrm{~s}, \Delta t_{P}=1 \mathrm{~s}$, due to its best performance of prediction [12].

A speed record algorithm was developed to acquire the speed profile record over the time period [tC $-\Delta \mathrm{tDC}$, $\mathrm{tC}$ ]. A characteristic-selection algorithm was developed using the recorded speed profile as the input and a set of twelve characteristics as the outputs. These twelve characteristics shown in Table 2 were labeled as C [i], (i $=1$, 2...12). A neural network for the prediction of drive cycles NNET_SDC was developed with C [i], ( $i=1,2 \ldots 12)$ as the input variables and with the SDC [i] as the output. The specific function framework of Prediction is shown in Figure 1.

\subsection{A Neural Network for the Prediction of Driving Trends}

The driving trends are short-term traffic state trends of a vehicle in the future. We divided the driving trends into five categories labeled with DT [i], $(i=1 \ldots 5)$, respectively, which are no speed, low speed cruise, high speed cruise, acceleration and deceleration. These five categories of driving trends correspond to five drive modes of a parallel hybrid electrical vehicle, i.e., corresponding to parking mode, motor driving mode, engine driving mode, engine and motor joint driving mode, and braking energy recovery mode respectively. More details on qualitative distinction are shown in Table 3.

The Operating Principles of the Neural Learning for Driving Trends: Supposed that DC $(t)$ is a real-time drive cycle of a certain trip that a driver is going to go through, $\left(t \in\left[0, t_{e}\right]\right.$, where $t_{e}$ is ending moment of the drive cycle). At any time $t$, the current drive cycle DC $(t)$ corresponds to one of five driving trends DT[ $i]$, $(i=$ 1...5). A neural network for the prediction of driving trends called NNET_DT was developed. NNET_DT identifies to which one of the five driving trends DT[i] the real-time drive cycle DC $(t)$ corresponds in the time segment $\left[t_{C}-\Delta t_{D T}, t_{C}\right]$, where $t_{C}$ is the current time instance, $\Delta t_{D T}$ is the window size of the time segment using for 


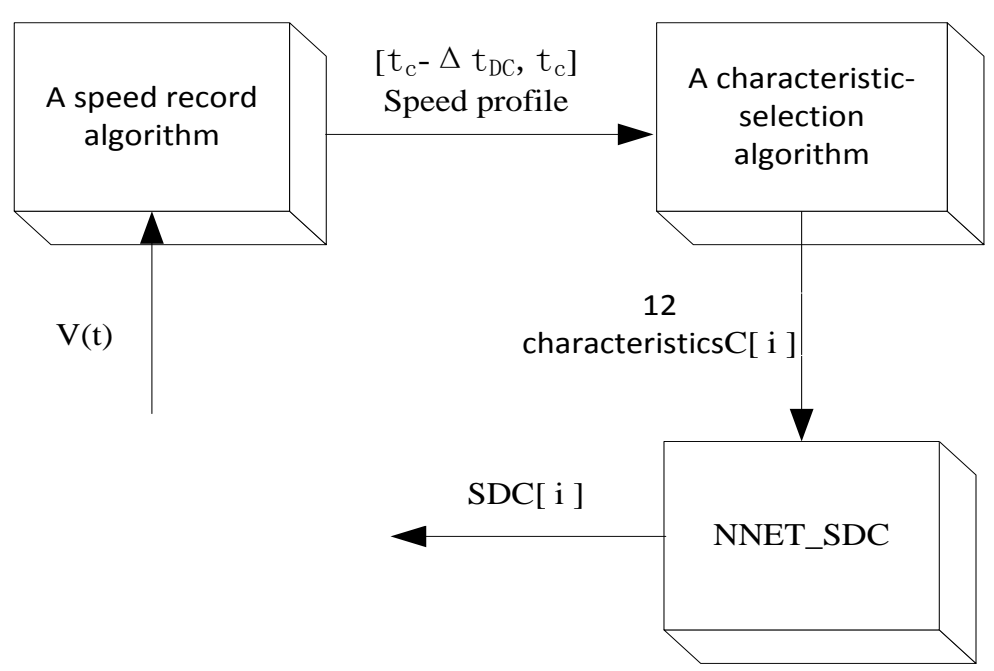

Figure 1. Function framework for predicted drive cycles.

Table 2. Twelve characteristics selected for drive-cycle prediction.

Description for the selected characteristics C [i]
C [1]: $\Delta$ S is the distance over $\left[t_{c}-\Delta t_{D C}, t_{c}\right]$
C [2]: $V_{\max }$ is the maximum speed over $\left[t_{c}-\Delta t_{D C}, t_{c}\right]$
C [3]: $V_{\text {avg }}$ is the average speed over $\left[t_{c}-\Delta t_{D C}, t_{c}\right]$
C [4]: $+\mathrm{A}_{\max }$ is the maximum acceleration over $\left[t_{c}-\Delta t_{D C}, t_{c}\right]$
C [5]: $+\mathrm{A}_{\text {avg }}$ is the average acceleration over $\left[t_{c}-\Delta t_{D C}, t_{c}\right]$
C [6]: - $A_{\text {max }}$ is the maximum deceleration over $\left[t_{c}-\Delta t_{D C}, t_{c}\right]$
C [7]: - $A_{\text {avg }}$ is the average deceleration over $\left[t_{c}-\Delta t_{D C}, t_{c}\right]$
C [8]: Percentage of time in speed interval $0-15 \mathrm{~km} / \mathrm{h}$ over $\left[t_{c}-\Delta t_{D C}, t_{c}\right]$
C [9]: Percentage of time in speed interval $15-30 \mathrm{~km} / \mathrm{h}$ over $\left[t_{c}-\Delta t_{D C}, t_{c}\right]$
C [10]: Percentage of time in speed interval $0-15 \mathrm{~km} / \mathrm{h}$ over $\left[t_{c}-\Delta t_{D C}, t_{c}\right]$
C [11]: Percentage of time in speed interval (-10) - $(-2.5) \mathrm{m} / \mathrm{s}^{2}$ over $\left[t_{c}-\Delta t_{D C}, t_{c}\right]$
C [12]: Percentage of time in speed interval (-2.5) - $(-1.5) \mathrm{m} / \mathrm{s}^{2}$ over $\left[t_{c}-\Delta t_{D C}, t_{c}\right]$

Table 3. Five classes of driving trends.

\begin{tabular}{ccc}
\hline Driving Trends DT [i] & Qualitative Distinction & Driving Pattern \\
\hline No speed DT [1] & $v=0$ & Parking mode \\
Low speed cruise DT [2] & $\left\{\begin{array}{c}0<v_{\text {ave }}<17.87 \mathrm{~m} / \mathrm{s} \\
-0.1524<A_{\text {ave }}<0.1524 \mathrm{~m} / \mathrm{s}^{2}\end{array}\right.$ \\
High speed cruise DT [3] & $\left\{\begin{array}{c}v_{\text {ave }}>17.87 \mathrm{~m} / \mathrm{s} \\
-0.1524<A_{\text {ave }}<0.1524 \mathrm{~m} / \mathrm{s}^{2} \\
A_{\text {ave }}>0.1524 \mathrm{~m} / \mathrm{s}^{2} \\
A_{\text {ave }}<-0.1524 \mathrm{~m} / \mathrm{s}^{2}\end{array}\right.$ & Motor driving mode \\
Acceleration DT [4] & Engine driving mode
\end{tabular}


the prediction of driving trends. And then we assume that the driving trend which a vehicle will be at over the time period $\left[t_{C}, t_{C}+\Delta t_{P}\right]$ is the same as the driving trend which the vehicle was at over the time period $\left[t_{C}-\Delta t_{D T}\right.$, $\left.t_{C}\right]$ in the past. Namely, we identify which the five driving trends DT[i] a vehicle was at over the time period $\left[t_{C}\right.$ $\left.-\Delta t_{D T}, t_{C}\right]$ in the past, and use the identical DT[i] to represent the driving trend which the vehicle will be at over the time period $\left[t_{C}, t_{C}+\Delta t_{P}\right]$ as the prediction of driving trend, where $\Delta t_{P}$ is the time interval over which the prediction is made. $\Delta t_{D T}=9 \mathrm{~s}$ and $\Delta t_{p}=1 \mathrm{~s}$ are selected as good window sizes due to the good performances of prediction.

The specific function framework of prediction is shown as Figure 2. Another speed record algorithm was developed to acquire the speed profile record over the time period $\left[t_{C}-\Delta t_{D T}, t_{C}\right]$. Another characteristic-selection algorithm was developed with the recorded speed profile as the input and a set of six variables as the outputs, namely: $v_{a v e}, v_{\max }, v_{\min }, a_{a v e}, v_{s t}$ and $v_{\text {end }}$, among them, the first four parameters are respectively the average speed, the maximum speed, the minimum speed, the average acceleration over the time period $\left[t_{C}-\Delta t_{D T}, t_{C}\right], v_{s t}$ is the starting time speed and $v_{\text {end }}$ is the ending time speed. A neural network for the prediction of driving trends NNET_DT was developed with six variables described above as the inputs and with the DT $[i]$ as the outputs.

The NNET_DT algorithm is a one-step prediction and multiclass neural network, with six input nodes, with a competitive layer and with five output nodes. The architecture of the network NNET_DT is shown in Figure 3.

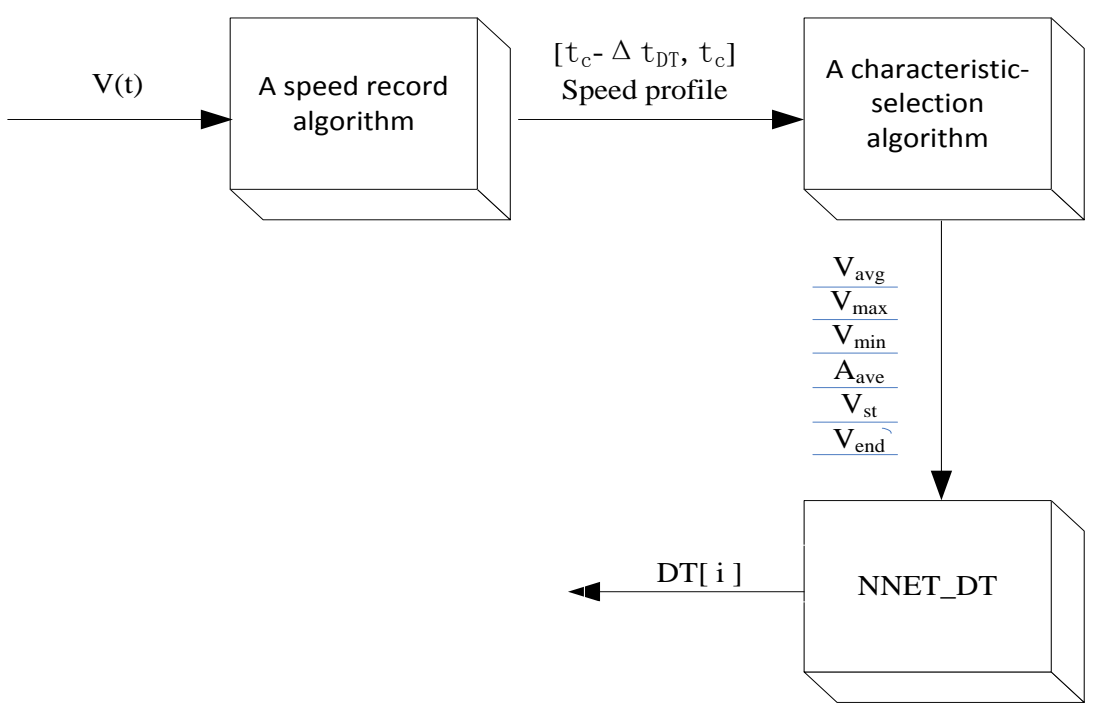

Figure 2. Function framework for predicted driving trends.

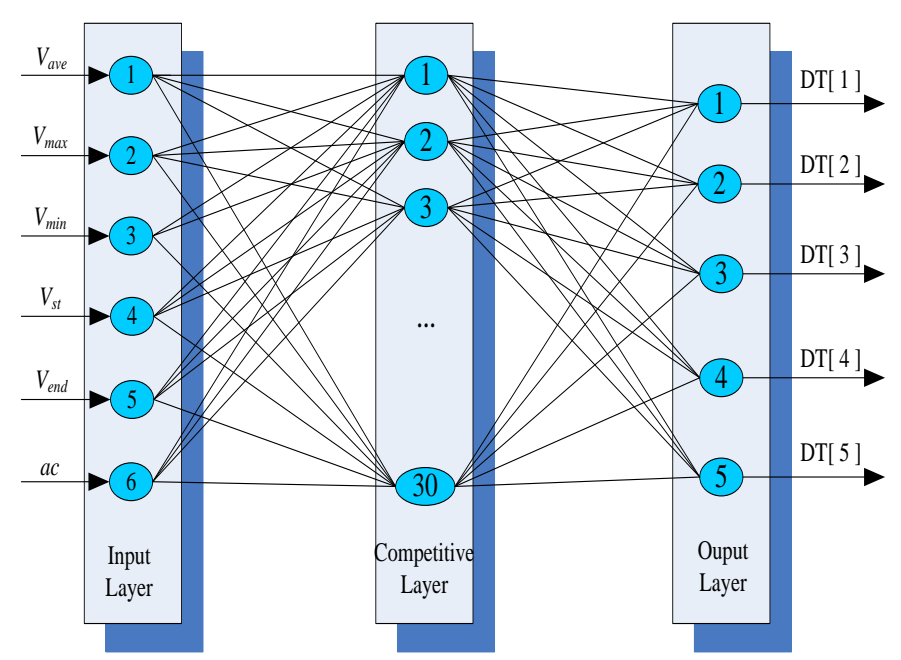

Figure 3. NNET_DT: The architecture of neural network for driving trends. 


\section{Intelligent Fuzzy Logic Controller}

This research was conducted based on a double-shaft parallel hybrid electrical vehicle. An intelligent fuzzy logic control system module FLCS_MODEL was built with the use of the Mat lab/Simulink [13] [14], as shown in Figure 4. The FLCS_MODEL is a control system module with four input variables, which are respectively the vehicle demand torque $T_{\text {veh_req }}$, SOC values of the battery, the predicted drive cycle SDC[i] and the predicted driving trend DT[i] for the time period $\left[t_{C}, t_{C}+\Delta t_{P}\right]$, and with the adjustment coefficient of engine torque $T_{w}$ as the output.

The fuzzy value range of the vehicle demand torque $T_{\text {veh_req }}$ is $\left\{T_{1}, T_{2}, T_{3}, T_{4}, T_{5}, T_{6}, T_{7}, T_{8}, T_{9}, T_{10}, T_{11}, T_{12}\right\}$, which domain of discourse is $[0,100]$. The membership function of $T_{\text {veh_req }}$ is shown in Figure 5. The fuzzy value range of SOC values of the battery is $\left\{S_{1}, S_{2}, S_{3}, S_{4}, S_{5}, S_{6}\right\}$, which domain of discourse is $[0,1]$. The membership function of SOC is shown in Figure 6. The fuzzy value range of the predicted drive cycle SDC[i] is $\left\{\mathrm{SDC}_{1}, \mathrm{SDC}_{2}, \mathrm{SDC}_{3} \ldots \mathrm{SDC}_{10}, \mathrm{SDC}_{11}\right\}$ with corresponding monodromy value of $[1,2,3 \ldots 10,11]$. The fuzzy value range of the predicted of driving trend $\mathrm{DT}[i]$ is $\left\{\mathrm{DT}_{1} \mathrm{DT}_{2}, \mathrm{DT}_{3}, \mathrm{DT}_{4}, \mathrm{DT}_{5}\right\}$ with corresponding monodromy value of $[1,2,3,4,5]$, where $\mathrm{DT}_{1}=1$ represents no speed (parking mode), $\mathrm{DT}_{2}=2$ represents low speed cruise (motor driving mode), $\mathrm{DT}_{3}=3$ represents high speed cruise (engine driving mode), $\mathrm{DT}_{4}=4$ represents acceleration (engine and motor joint driving mode) and $\mathrm{DT}_{5}=5$ means deceleration (braking energy recovery mode). The fuzzy value range of the adjustment coefficient of engine torque $T_{w}$ is $\left\{K_{1}, K_{2}, K_{3}, K_{4}, K_{5}, K_{6}, K_{7}\right.$, $\mathrm{K}_{8}, \mathrm{~K}_{9}, \mathrm{k}_{10}, \mathrm{~K}_{11}, \mathrm{~K}_{12}, \mathrm{~K}_{13}, \mathrm{~K}_{14}, \mathrm{~K}_{15}, \mathrm{~K}_{16}$, which domain of discourse is [0, 1]. The membership function of $T_{w}$ is shown in Figure 7.

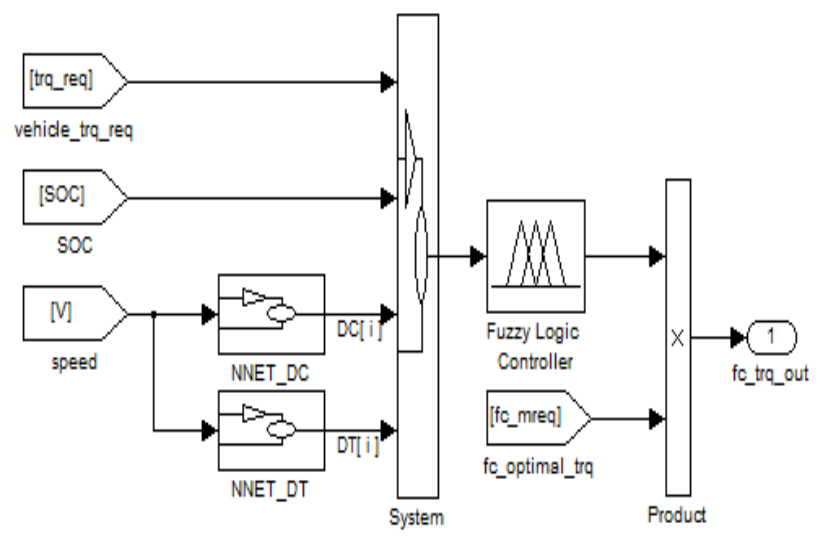

Figure 4. The intelligent fuzzy logic control system module.

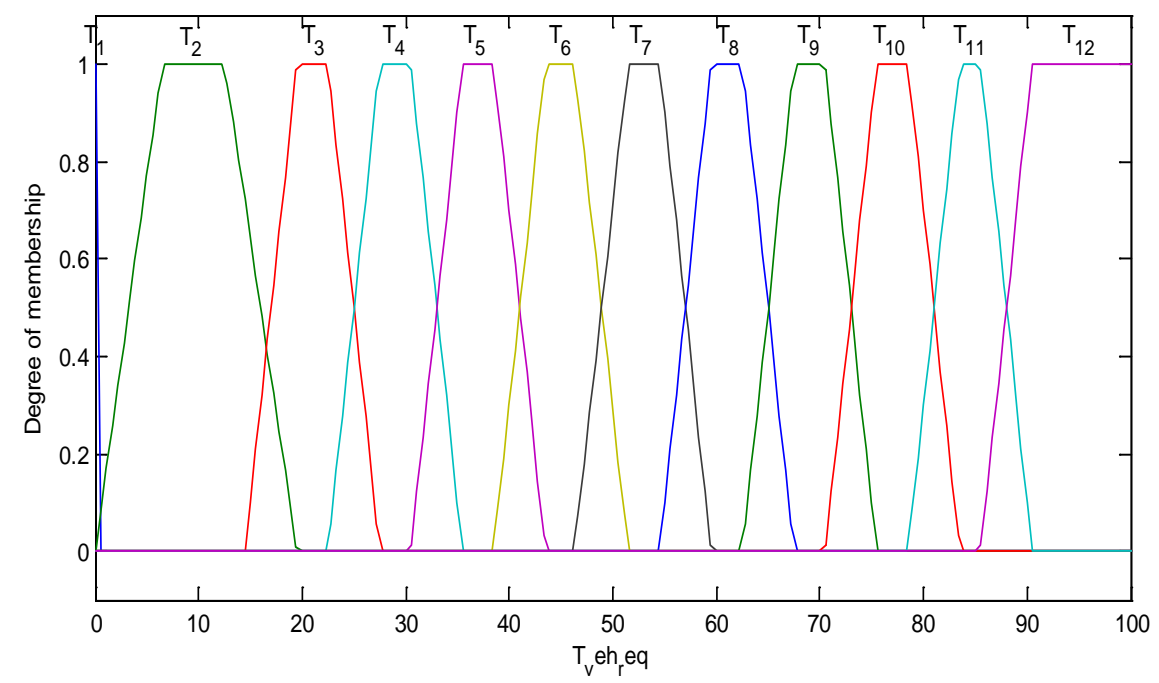

Figure 5. The membership function of $\mathrm{T}_{\text {veh_req. }}$ 


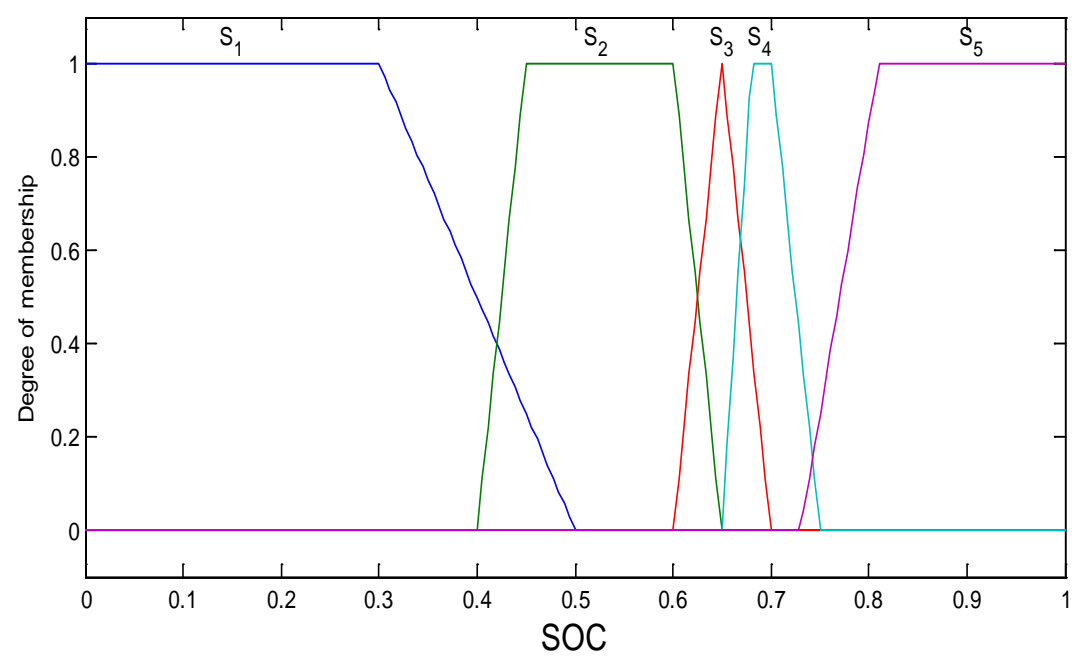

Figure 6. Membership function of SOC.

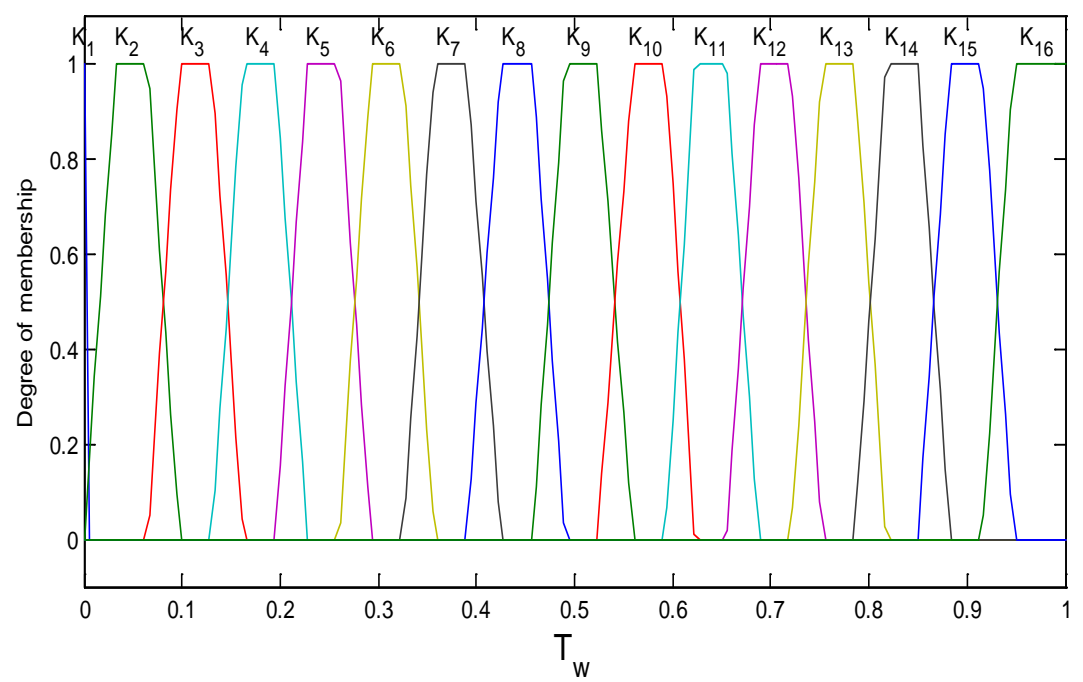

Figure 7. Membership function of the adjustment coefficient of engine torque.

\subsection{The Fuzzy Control Rules}

The linguistic variables of input and output are used as the trapezoid membership function or triangle membership function [15]. AND operation is computed by minimum method. Defuzzifying is implemented with the center-of-gravity method. To refine the fuzzy control rules and make sure that the output torque of engine is able to adjust to different kinds of situations, we divided fuzzy range of the inputs and the outputs into multiple areas. Because there are four input variables and the scope of each variable is big, there are a lot of the fuzzy control rules. This paper only lists some of the main rules as follows. If $T_{\text {veh_req }}$ is $\mathrm{T}_{1}$ and SOC is $\mathrm{S}_{3}$ then $T_{w}$ is $\mathrm{K}_{1}$.

If $T_{\text {veh_req }}$ is $\mathrm{T}_{1}$ and SOC is $\mathrm{S}_{2}$ and SDC[i] is $\mathrm{SDC}_{11}$ and DT[i] is $\mathrm{DT}_{2}$ then $T_{w}$ is $\mathrm{K}_{5}$.

If $T_{\text {veh_req }}$ is $\mathrm{T}_{2}$ and SOC is $\mathrm{S}_{1}$ and SDC[i] is $\mathrm{SDC}_{1}$ and DT[i] is $\mathrm{DT}_{2}$ then $T_{w}$ is $\mathrm{K}_{7}$.

If $T_{\text {veh_req }}$ is $\mathrm{T}_{2}$ and SOC is $\mathrm{S}_{1}$ and SDC[i] is $\mathrm{SDC}_{1}$ and DT[i] is $\mathrm{DT}_{3}$ then $T_{w}$ is $\mathrm{K}_{9}$.

If $T_{\text {veh_req }}$ is $\mathrm{T}_{2}$ and SOC is $\mathrm{S}_{2}$ and SDC[i] is $\mathrm{SDC}_{1}$ and DT[i] is $\mathrm{DT}_{2}$ then $T_{w}$ is $\mathrm{K}_{6}$.

If $T_{\text {veh_req }}$ is $\mathrm{T}_{2}$ and SOC is $\mathrm{S}_{2}$ and SDC[i] is $\mathrm{SDC}_{1}$ and DT[i] is $\mathrm{DT}_{3}$ then $T_{w}$ is $\mathrm{K}_{7}$.

If $T_{\text {veh_req }}$ is $\mathrm{T}_{2}$ and SOC is $\mathrm{S}_{3}$ and SDC[i] is $\mathrm{SDC}_{11}$ and DT[i] is $\mathrm{DT}_{2}$ then $T_{w}$ is $\mathrm{K}_{1}$.

If $T_{\text {veh_req }}$ is $\mathrm{T}_{2}$ and SOC is $\mathrm{S}_{4}$ and SDC[i] is $\mathrm{SDC}_{11}$ and DT[i] is $\mathrm{DT}_{2}$ then $T_{w}$ is $\mathrm{K}_{1}$.

If $T_{\text {veh_req }}$ is $\mathrm{T}_{2}$ and SOC is $\mathrm{S}_{5}$ and $\mathrm{SDC}[i]$ is $\mathrm{SDC}_{11}$ and DT[i] is $\mathrm{DT}_{2}$ then $T_{w}$ is $\mathrm{K}_{1}$. 
If $T_{\text {veh_req }}$ is $\mathrm{T}_{9}$ and SOC is $\mathrm{S}_{2}$ and SDC[i] is $\mathrm{SDC}_{8}$ and DT[i] is $\mathrm{DT}_{4}$ then $T_{w}$ is $\mathrm{K}_{13}$.

If $T_{\text {veh_req }}$ is $\mathrm{T}_{10}$ and SOC is $\mathrm{S}_{4}$ and SDC[i] is $\mathrm{SDC}_{11}$ and DT[i] is $\mathrm{DT}_{2}$ then $T_{w}$ is $\mathrm{K}$.

1. If the vehicle demand torque $T_{\text {veh_req }}$ is zero, the vehicle would be in a state of stop or braking. And if SOC value of the battery is within the normal range or on the high side; the output torque of engine will be zero no matter what the predicted drive cycle and what the predicted driving trend are.

2. If the vehicle demand torque $T_{\text {veh_req }}$ is zero, SOC value of the battery is low, the vehicle drives on local road over the time period $\left[t_{C}, t_{C}+\Delta t_{P}\right]\left(\mathrm{SDC}[i]=\mathrm{SDC}_{11}\right)$, and the driving trend is low speed cruise (DT [i] $=$ $\mathrm{DT}_{2}$ ), part of the engine output torque will be required to recharge the battery.

3. If the vehicle demand torque $T_{\text {veh_req }}$ is small, SOC values of the battery is low, the drive cycle is freeway A $\left(\mathrm{SDC}[i]=\mathrm{SDC}_{1}\right)$ and the driving trend is low speed cruise $\left(\mathrm{DT}[i]=\mathrm{DT}_{2}\right)$ over the time period $\left[t_{C}, t_{C}+\Delta t_{P}\right]$, a reasonable large engine output torque will be required to recharge the battery for ensuring that there is enough electrical power in the battery for the motor to propel the vehicle alone.

4. If the vehicle demand torque $T_{\text {veh_req }}$ is small, SOC value of the battery is low, the drive cycle is freeway A $\left(\mathrm{SDC}[i]=\mathrm{SDC}_{1}\right)$ and the driving trend is high speed cruise $\left(\mathrm{DT}[i]=\mathrm{DT}_{3}\right)$ over the time period $\left[t_{C}, t_{C}+\Delta t_{P}\right]$, then a reasonable small engine output torque will be distributed to the battery for recharging. However, with the consideration of the predicted drive cycle and driving trend, the total engine output torque should be slightly large.

5. If the vehicle demand torque $T_{\text {veh_req }}$ is small, the SOC value of the battery is within the normal range or on the high side, the vehicle drives in local road over the time period $\left[t_{C}, t_{C}+\Delta t_{P}\right]\left(\mathrm{SDC}[i]=\mathrm{SDC}_{11}\right)$, and the driving trend is low speed cruise $\left(\mathrm{DT}[i]=\mathrm{DT}_{2}\right)$, then the output torque of engine will be zero, the vehicle will be at motor driving mode.

6. If the vehicle demand torque $T_{\text {veh_req }}$ is medium, the SOC value of the battery is within the normal range or on the low side, the drive cycle is freeway $\mathrm{B}\left(\mathrm{SDC}[i]=\mathrm{SDC}_{2}\right)$ and the driving trend is low speed cruise (DT[i] = $\mathrm{DT}_{2}$ ) over the time period $\left[t_{C}, t_{C}+\Delta t_{P}\right]$, then the engine should be operated in high efficiency workspace and the SOC value should be maintained in a regular range.

7. If the vehicle demand torque $T_{\text {veh_req }}$ is medium, the SOC value of the battery is on the high side, the drive cycle is freeway $\mathrm{B}\left(\mathrm{SDC}[i]=\mathrm{SDC}_{2}\right)$ and the driving trend is high speed cruise $\left(\mathrm{DT}[\mathrm{i}]=\mathrm{DT}_{3}\right)$ over the time pe$\operatorname{riod}\left[t_{C}, t_{C}+\Delta t_{P}\right]$, then the engine will propel the vehicle and the engine should be operated in high efficiency workspace.

8. If the vehicle demand torque $T_{\text {veh_req }}$ is large, the SOC value of the battery is within the normal range or on the high side, and no matter what the predicted drive cycle is and what the predicted driving trend is, then the engine should be operated in high efficiency workspace and output the maximum corresponding torque, and the insufficient will be made up from the motor.

9. If the vehicle demand torque $T_{\text {veh_req }}$ is large, the SOC value of the battery is on the low side, and no matter what the predicted drive cycle is and what the predicted driving trend is, then the output torque of engine should be a little bit larger than the vehicle demand torque $T_{\text {veh_req }}$ to recharge the battery for the desired range.

\subsection{The Implementation the FLCS_MODEL}

The established fuzzy logic control module was embedded in the vehicle model of the simulation software ADVISOR2002. Figure 8 shows the fuzzy logic control module in the vehicle module. The FLCS_MODEL was integrated between the driving module and subsystems. The control computing steps of the FLCS_MODEL are as follows:

Step 1: compare the size of $\mathrm{t}$ with the size of $\Delta \mathrm{tDC}$, if $\mathrm{t} \geq \Delta \mathrm{tDC}=50 \mathrm{~s}$, then go to step 2. Otherwise, the vehicle will be drove with the initial setting; compare the size of $\mathrm{t}$ with the size of $\Delta \mathrm{tDT}$, if $\mathrm{t} \geq \Delta \mathrm{tDT}=9 \mathrm{~s}$, then go to step 3. Otherwise, the vehicle will be drove with the initial setting.

Step 2: the fuzzy logic controller calls NNET_SDC to predict the drive cycle SDC[i] for the time period [tC, $\mathrm{tC}+\Delta \mathrm{tP}]$.

Step 3: the fuzzy logic controller calls NNET_DT to predict the driving trends DT[i] for the time period [tC, $\mathrm{tC}+\Delta \mathrm{tP}]$.

Step 4: If the step 2 and the step 3 are positive simultaneously, then the FLCS_MODEL will be fully activated with the adjustment coefficient of engine torque Tw as the output.

Step 5: the final output torque of engine is calculated based on the adjustment coefficient of engine torque Tw, and is then input to the ECU of the engine. 


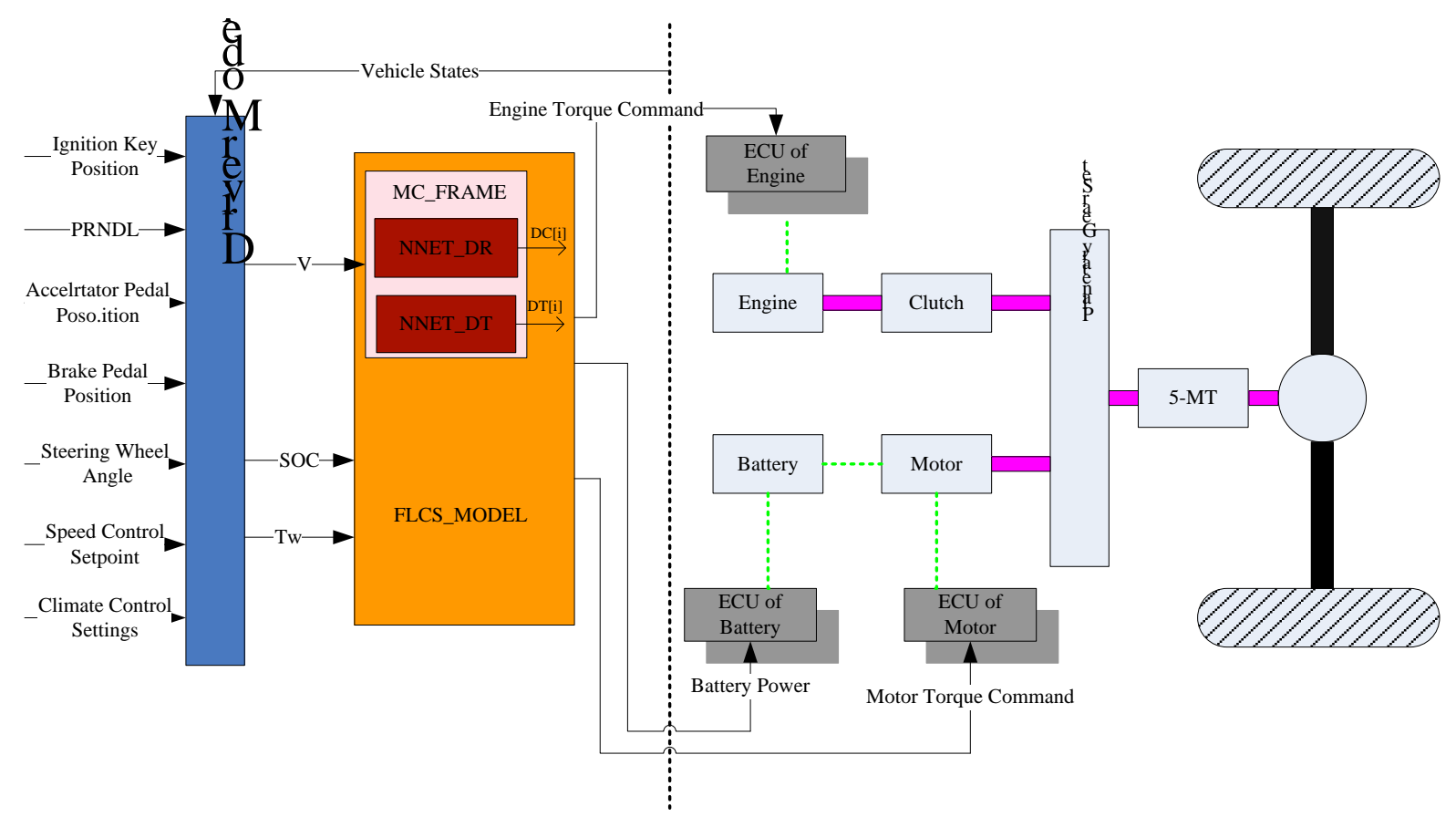

Figure 8. Implementation of the FLCS_MODEL in a vehicle system model.

Step 6: the distributed output torque of the motor is computed according to dynamics and kinematics equations of the power train. The calculated motor torque is then input to the ECU of the motor.

\section{Simulation and Results}

In order to evaluate the intelligent fuzzy logic controller which we had established on the base of the prediction module MC_FRAME, i.e., to evaluate its effectiveness and its performances on the interests of energy conservation and emission reduction, an experiment was conducted to do the simulation analysis by using the advanced vehicle simulation software ADVISOR. A certain parallel hybrid electrical vehicle (PHEV) was selected for simulation. The intelligent controller FLCS_MODEL was embedded in the selected vehicle model of the simulation software ADVISOR2002. The performance parameters of the selected PHEV for simulation are listed in Table 4. The NEDC was, respecting the driving conditions in an urban city for light trucks and passenger cars, chosen for simulation as a drive cycle.

Figure 9 shows the simulation curves of intelligent controller FLCS_MODEL on the drive cycle NEDC. Figure 10 shows the simulation curves of the default control strategy on the drive cycle NEDC. These two figures show that both the FLCS_MODEL and the default control strategy have a good control on the SOC values of the battery. Besides, the SOC curves of these two strategies are that similar. However, the ending SOC value of the FLCS_MODEL is a little bit lower than the ending SOC value of the default controller, which means the discharge magnitude of the FLCS_MODEL, is lager over that of the default controller. The FLCS_MODEL achieves less the exhaust emissions than the default control strategy. All the terms of emissions reduce except for the HC emissions, from which we can conclude that the FLCS_MODEL control strategy in an urban city for light trucks or passenger cars has advantages in emission controls.

Table 5 is the simulation results on the drive cycle NEDC. As it is showed in the table, comparing with the default control strategy on the drive cycle NEDC, the FLCS_MODEL control strategy saves $13.46 \%$ fuel per hundred kilometers, with the $\mathrm{HC}$ emissions increasing by $23.5 \%$, the $\mathrm{CO}$ emissions reducing by $17 \%$, the $\mathrm{NO}_{\mathrm{x}}$ emissions reducing by $38.6 \%$, and with the PM emissions reducing by $12.9 \%$. As for the dynamic performance, the 0 -to- $96.6 \mathrm{~km} / \mathrm{h}$ acceleration time increases by $25.3 \%$. This suggests that, on the drive cycle NEDC, the intelligent controller FLCS_MODEL gives a better performance on energy conservation than the default one. As for emissions, all the terms of emissions are improved except for the HC emissions. In general, the performances on energy conservation and emission reduction are improved. 


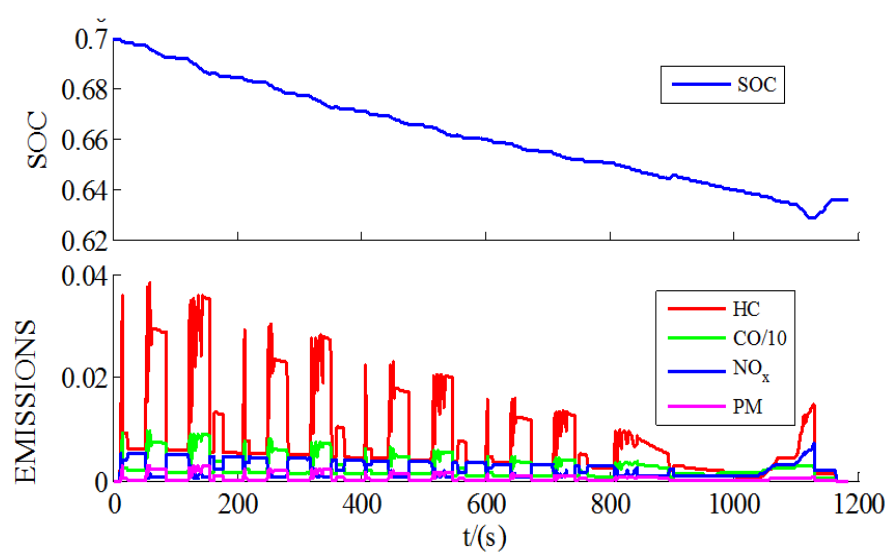

Figure 9. Simulation curves of the FLCS_MODEL.

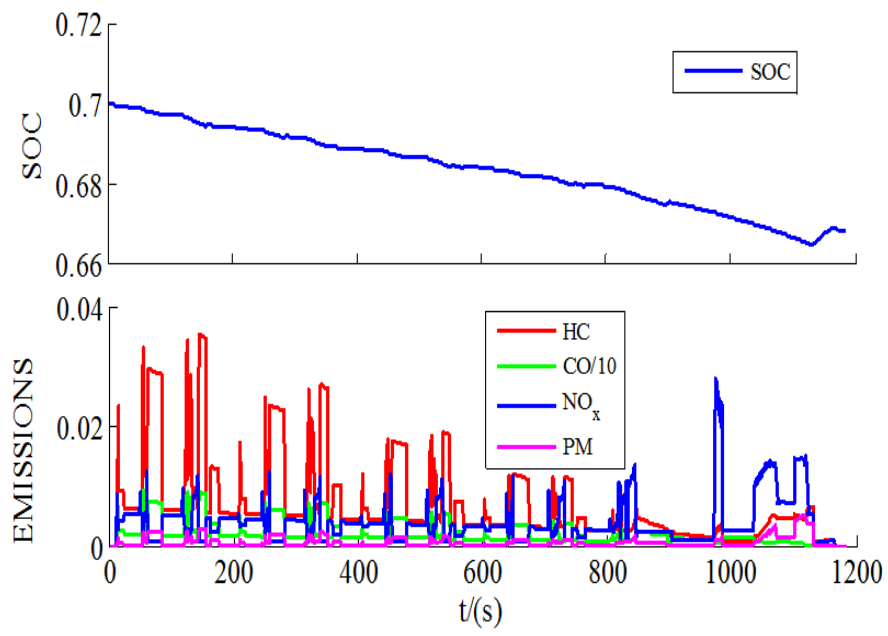

Figure 10. Simulation curves of the default control strategy.

Table 4. The simulation parameters of the main components.

\begin{tabular}{cc}
\hline Parameters & Value \\
\hline Vehicle mass (kg) & 1645 \\
Dynamic rolling radium (m) & 0.298 \\
Engine power (KW) & 65 \\
Motor/generator power (KW) & 21 \\
Battery capacity (A.h) & 400 \\
\hline
\end{tabular}

Table 5. Simulation results.

\begin{tabular}{cccc}
\hline Items & Names & FLCS_MODEL & Default \\
\hline Dynamic performance & $0-96.6 \mathrm{~km} / \mathrm{h}$ acceleration time $(\mathrm{s})$ & 12.4 & 9.9 \\
Fuel consumption & $\mathrm{Q}(\mathrm{L} / 100 \mathrm{~km})$ & 4.5 & 5.2 \\
& $\mathrm{HC}(\mathrm{g} / \mathrm{km})$ & 0.899 & 0.728 \\
Emissions & $\mathrm{CO}(\mathrm{g} / \mathrm{km})$ & 1.821 & 2.194 \\
& $\mathrm{NO}(\mathrm{g} / \mathrm{km})$ & 0.264 & 0.43 \\
& $\mathrm{PM}(\mathrm{g} / \mathrm{km})$ & 0.061 & 0.07 \\
\hline
\end{tabular}




\section{Conclusion}

In this paper, we have presented a machine learning framework called MC_FRAME as a prediction model with a neural network NNET_SDC for the prediction of drive cycles and another neural network NNET_DT for the prediction of driving trends. Besides, the operating principles of both the NNET_SDC and the NNET_DT have also been presented. We have designed an intelligent fuzzy logic control strategy FLCS_MODEL based on prediction module MC_FRAME. The FLCS_MODEL that incorporates the knowledge about real-time predicted drive cycles and the predicted driving trends is more intelligent and more real-time. We used the simulation software ADVISOR to conduct experiments. Our simulation results on the drive cycle NEDC show that the intelligent controller FLCS_MODEL is reasonable, and it achieves a better performance on energy conservation and emissions reduction over the default control strategy in the PHEV we used for simulation. Our next research is to combine the prediction module framework MC_FRAME with multi-agent technologies. We are looking forward to a more intelligent integrated control system of power train in a hybrid electrical vehicle will be achieved, which aims for the optimal vehicle power management with the consideration of the optimal output of every single component.

\section{Acknowledgements}

This work is supported by National Natural Science Foundation of China (51275002) and Creative Foundation for Graduate Students of Anhui University of Technology (2014058).

\section{References}

[1] Guo, X.J. and Zhen, W.Y. (2015) Toyota Hybrid Electrical Vehicles. Auto Review, 1, 61-63.

http://www.cnki.net/KCMS/detail/detail.aspx?QueryID=4\&CurRec=14\&dbcode=CJFQ\&dbname=CJFDLAST2015\&fil name=QCZH201501017\&urlid=\&yx=\&uid=WEEvREcwSIJHSldSdnQ0THQ2bHRLYUxyeVFhcFVmTFJTbmljcDZ LY1ArK3Z5R3pWbExSTUp6QmlCSzdiR0Fta3JRPT0=\$9A4hF YAuvQ5obgVAqNKPCYcEjKensW4IQMovwHtwk F4VYPoHbKxJw!!\&v=MTc2NzMzcVRyV00xRnJDVVJMK2ZidVp0RnlubFVMN09OQzdSWnJHNEg5VE1ybzlFW TRSOGVYMUx1eFITNORoMVQ

[2] Johnson, V.H., Wipke, K.B. and Rausen, D.J. (2000) HEV Control Strategy for Real-Time Optimization of Fuel Economy and Emissions. 2000 Future Car Congress, SAE International, Arlington, 2-6 April 2000.

[3] Ericsson, E. (2001) Independent Driving Pattern Factors and Their Influence on Fuel-Use and Exhaust Emission Factors. Transportation Research Part D: Transport and Environment, 6, 325-345.

http://www.engineeringvillage.com/search/doc/abstract.url?pageType=quickSearch\&searchtype=Quick\&SEARCHID= 88b75529M18c5M4c96M8df7Mfa32bbaf032b\&DOCINDEX=1\&database=1\&format=quickSearchAbstractFormat\&d edupResultCount=\&SEARCHID=88b75529M18c5M4c96M8df7Mfa32bbaf032b http://dx.doi.org/10.1016/S1361-9209(01)00003-7

[4] Jeon, S.-I., Jo, S.-T., Park, Y.-I. and Lee, J.-M. (2002) Multi-Mode Driving Control of a Parallel Hybrid Electric Vehicle Using Driving Pattern Recognition. Journal of Dynamic Systems, 124, 141-149.

http://www.engineeringvillage.com/search/doc/abstract.url?pageType=quickSearch\&searchtype=Quick\&SEARCHID= 41abe672M67c9M4bcfM92b4M6b20bd87e633\&DOCINDEX=1\&database=1\&format=quickSearchAbstractFormat\& dedupResultCount=\&SEARCHID=41abe672M67c9M4bcfM92b4M6b20bd87e633 http://dx.doi.org/10.1115/1.1434264

[5] Langari, R. and Won, J.S. (2005) Intelligent Energy Management Agent for a Parallel Hybrid Vehicle-Part I: System Architecture and Design of the Driving Situation Identification Process. IEEE Transactions on Vehicular Technology, 54, 925-934.

http://www.engineeringvillage.com/search/doc/abstract.url?pageType=quickSearch\&searchtype=Quick\&SEARCHID= 5f96548cM348aM4300Mb688M936815dad90b\&DOCINDEX=1\&database=1\&format=quickSearchAbstractFormat\& dedupResultCount=\&SEARCHID=5f96548cM348aM4300Mb688M936815dad90b http://dx.doi.org/10.1109/TVT.2005.844685

[6] Won, J.S. and Langari, R. (2005) Intelligent Energy Management Agent for a Parallel Hybrid Vehicle-Part II: Torque Distribution, Charge Sustenance Strategies, and Performance Results. IEEE Transactions on Vehicular Technology, 54, 935-953.

http://www.engineeringvillage.com/search/doc/abstract.url?pageType=quickSearch\&searchtype=Quick\&SEARCHID= fe890fefM090fM4fd5M9200Mf60746f2aac6\&DOCINDEX=1\&database=1\&format=quickSearchAbstractFormat\&de dupResultCount=\&SEARCHID=fe890fefM090fM4fd5M9200Mf60746f2aac6 http://dx.doi.org/10.1109/TVT.2005.844683 
[7] Wang, Q.N., Tang, X.Z., Wang, P.Y., Tian, L.Y. and Sun, L. (2012) Driving Intention Identification Method for Hybrid Vehicles Based on Neural Network (in Chinese). Transactions of the Chinese Society of Agricultural Machinery, 43, 32-36.

http://www.engineeringvillage.com/search/doc/abstract.url?pageType=quickSearch\&searchtype=Quick\&SEARCHID= 4fea91d4M32e7M4ed3Ma0c2Me99e9dd3b725\&DOCINDEX=1\&database=1\&format=quickSearchAbstractFormat\&d edupResultCount=\&SEARCHID=4fea91d4M32e7M4ed3Ma0c2Me99e9dd3b725

[8] Lv, R.Z. (2013) Control Strategy of HEV Base on the Driving Cycle and Driver Intention Recognition (Chinese). MA.SC. Thesis, Dalian University of Technology, Dalian.

[9] Yang, G.L. (2014) Energy Management Strategy of Plug-In Hybrid Electric Vehicle Based on the Recognition of Driving Intention and Working Condition (Chinese). Ph.D. Thesis, Chongqing University, Chongqing.

[10] Jin, Y., Xie, Z.F., Chen, J.B. and Chen, E.Y. (2015) PHEV Power Distribution Fuzzy Logic Control Strategy Based on Prediction (in Chinese). Journal of Zhejiang University of Technology, 43, 97-102.

http://www.cnki.net/KCMS/detail/detail.aspx?QueryID=18\&CurRec=1\&recid=\&filename=ZJGD201501019\&dbname =CJFDLAST2015\&dbcode=CJFQ\&pr=\&urlid=\&yx=\&uid=WEEvREcwSIJHSldSdnQ0THZscFNkZ0tSczZFUk0xQT RvYmlNV21sSEkvMm9RdzFMUU5FK1ppQndINHFsREpaWlh3PT0=\$9A4hF YAuvQ5obgVAqNKPCYcEjKensW 4IQMovwHtwkF4VYPoHbKxJw!!\&v=MDk1MDNMdXhZUzdEaDFUM3FUcldNMUZyQ1VSTCtmYnVackZpRGh VTHZOUHImTWFyRzRIOVRNcm85RWJZUjhlWDE

[11] Zhang, B.L., Zhang, P.P., Zhao, G., Tian, F., Xu, X.D., et al. (2010) Fuel Economy Global Optimal Control of PHEV Based on Discrete Dynamic Programming (in Chinese). Automotive Engineering, 32, 923-927.

http://www.cnki.net/KCMS/detail/detail.aspx?QueryID=0\&CurRec=1\&recid=\&filename=QCGC201011000\&dbname $=$ CJFD2010\&dbcode $=$ CJFQ\&pr=\&urlid=\&yx=\&uid=WEEvREcwSIJHSldSdnQ0THZscFNkZ0tSczZFUk0xQTRvYm INV21sSEkvMm9RdzFMUU5FK1ppQndINHFsREpaWlh3PT0=\$9A4hF_YAuvQ5obgVAqNKPCYcEjKensW4IQM ovwHtwkF4VYPoHbKxJw!!\&v=MDAwNDFyQ1VSTCtmYnVackZ5bmtWci9PTkM3TWJiRzRIOUhOcm85RlpJUjh IWDFMdXhZUzdEaDFUM3FUcldNMUY

[12] Park, J., Chen, Z.H., Kiliaris, L., Kuang, M.L., Masrur, M.A., et al. (2009) Intelligent Vehicle Power Control Based on Machine Learning of Optimal Control Parameters and Prediction of Road Type and Traffic Congestion. IEEE Transactions on Vehicular Technology, 58, 4741-4756.

http://www.engineeringvillage.com/search/doc/abstract.url?pageType=quickSearch\&searchtype=Quick\&SEARCHID= ffe464b2M0147M4507Mb382M7a0f8a1af3b0\&DOCINDEX=1\&database=1\&format=quickSearchAbstractFormat\&d edupResultCount=\&SEARCHID=ffe464b2M0147M4507Mb382M7a0f8a1af3b0 http://dx.doi.org/10.1109/TVT.2009.2027710

[13] Karl, P. and Werner, S. (Germany) (2012) Ground Vehicle Dynamics. Translator: Wu, G.Q., China Communications Press, Beijing.

[14] Antoni, S. (Poland) (2001) Hybrid Electric Vehicles Basis. Translator: Chen, Q.Q. and Sun, F.C., Beijing Institute of Technology Press, Beijing.

[15] Yang, S.C., Zhu, C.G., Gao, Y. and Li, J. (2011) A Research on Genetic Fuzzy Logic Control Strategy for Parallel Hybrid Vehicles. Automotive Engineering, 33, 106-111.

http://www.cnki.net/KCMS/detail/detail.aspx?QueryID=0\&CurRec=2\&recid=\&filename=QCGC201102006\&dbname =CJFD2011\&dbcode=CJFQ\&pr=\&urlid=\&yx=\&uid=WEEvREcwSIJHSIdSdnQ0THZscFNkZ0tSczZFUk0xQTRvYm INV21sSEkvMm9RdzFMUU5FK1ppQndINHFsREpaWlh3PT0=\$9A4hF_YAuvQ5obgVAqNKPCYcEjKensW4IQM ovwHtwkF4VYPoHbKxJw!!\&v=MjMyODFDN01iYkc0SDlETXJZOUZZb1I4ZVgxTHV4WVM3RGgxVDNxVHJX TTFGckNVUkwrZmJ1WnJGeW5tV3JySU4 